\title{
Reduction of the Additives Migration from Poly Vinyl Chloride Films by the Use of Permanent Plasticizers
}

\author{
M. O. Boussoum ${ }^{1,2}$, N. Belhaneche-Bensemra' ${ }^{2}$ \\ ${ }^{1}$ Faculté des Sciences de la Nature et de la Vie, Université de Tiaret, Algérie \\ ${ }^{2}$ Ecole Nationale Polytechnique, BP 182, El-Harrach, Alger, Algérie \\ Email: idir boussoum@yahoo.fr, nbelhaneche@yahoo.fr
}

Received April 2014

\begin{abstract}
This aim of this work is to study the partial replacement of the plasticizer ordinarily used di-octyl phtalate (DOP) by the permanent plasticizers ethylene-vinyl-acetate (EVA) and acrylonytrile-butadiene-styrene (ABS) in order to reduce migration of additives initially contents in polyvinyl chloride (PVC) stabilized with expoxidized sunflower oil (ESO). Migration tests with agitation to $40^{\circ} \mathrm{C}$ in sunflower oil and ethanol at $15 \%$ were made. Migration phenomenon was studied on the basis of the PVC samples mass variations, Fourier transform infrared spectroscopy (FTIR) and scanning electron microscope (SEM) analysis. The results showed the effectiveness of the approach consisting in the partial substitution of DOP by plasticizers of polymeric nature. The following order concerning the migration of additives was found: DOP (40) > DOP:EVA > (30/10) DOP:ABS (30/10). Furthermore, all the measured values of overall migrations were lower than the maximum allowable overall migration: $10 \mathrm{mg} \cdot \mathrm{dm}^{-2}$.
\end{abstract}

\section{Keywords}

PVC, Migration, DOP, Permanent Plasticizers, Mass Variation, FTIR Spectroscopy, SEM

\section{Introduction}

Poly (vinyl chloride) is a widely used polymer in the plastics industry due to its excellent properties. Nevertheless, the low thermal stability is one of its main disadvantages. It undergoes severe degradation via zip elimination of $\mathrm{HCl}$ at relatively low temperatures. To increase the heat stability of PVC, different metal soaps like Pb, $\mathrm{Cd}, \mathrm{Ca}$ and Zn carboxylates and some di- and mono-alkyltin compounds are used. Several inorganic lead compounds and organic secondary stabilizers (epoxides, polyols, phosphites, $\beta$-diketones) are also used in industrial recipes (Murphy, 2003). Furthermore, various additives such as plasticizers (phthalic and phosphoric acids, etc.) and lubricants are generally incorporated. Such substances are necessary for achieving the desired chemical and mechanical properties. For example, plasticizers are added to give elasticity (Murphy, 2003). But, despite their high compatibility with PVC, these low molecular weight additives possess a high mobility. In contrast to the macromolecules, these additives can migrate from the packaging material into the packed product causing qual- 
ity defects. These are shown as changes in odour and taste or as toxicological symptoms after ingestion (Figge, 1972). This problem of migration obviously has health consequences.

Plasticizers and phthalates in particular have been used in the production of flexible PVC for over 50 years for applications ranging from cable and wire covers and children's toys to medical devices and consumers products. During the past 20 years, phthalates have come under considerable attention from media, legislative and environmental concerns (Cadogan, 2002; Mersiowsky, 2002; Rahman \& Brazel, 2004). Although no direct evidence has been found of the toxic effect of phthalates to human beings, it has been proved that high dosage and long term exposure of phthalates to rodents resulted in liver cancer and adverse effect on the reproductive development for young male rats (Wilkinson \& Lamb, 1990). In addition phthalates were suspected of increasing asthma and bronchial obstruction in children (Oil, Hersong, \& Madsen, 1997).

There have been many studies on the phenomenon of migration (Marin, Lopez, Sanchez, Vilaplana, \& Jimenez, 1998; Belhaneche-Bensemra, Zeddam, \& Ouahmed, 2002; Earls, Axord, \& Braybrook, 2003; Marcilla, Garcia, \& Garcia-Quesada, 2004, 2007; Wang \& Storm, 2005; Atek \& Belhaneche-Bensemra, 2005; Boussoum, Atek, \& Belhaneche-Bensemra, 2006; Ito, Sechimi, Miura, Kawagushi, Saito, \& Nakazawa, 2006; Zeddam \& Belhaneche-Bensemra, 2010; Atek, Belhaneche-Bensemra, \& Turki, 2010), but few on reducing it. Various methods have been proposed to reduce the migration of plasticizers and other additives from plastic food packaging materials (Rahman \& Brazel, 2004):

1) Surface modification: surface crosslinking, modification of surface hydrophilicity/lipophilicity; surface coating; surface extraction.

2) Use of polymeric plasticizers and oligomers.

3) Use of alternative plasticizers.

4) Alternative polymers.

The aim of this work is to study the partial substitution of the commonly used plasticizer DOP by the permanent plasticizers EVA and ABS in order to reduce the migration of the additives in PVC stabilized with epoxidized sunflower oil, to identify the migrating substances and to compare the effectiveness of both permanent plasticizers. Such permanent plasticizers can increase cohesion within the molecules, thus reducing the release of additives into the food (Audic, Reyx, Brosse, \& Poncin-Epaillard, 2000). Migration is negligible because the plasticizers have a high molecular weight.

In this work, various formulations in the absence and presence of two permanent plasticizers (EVA and ABS) were prepared.

The migration tests were carried out with stirring at $40^{\circ} \mathrm{C}$ in two food simulants, namely, olive oil and $15 \%$ aqueous ethanol.

The mass variation of the PVC samples with time was investigated. Migration phenomena were studied by using various analytical methods such as Fourier transform infrared spectroscopy (FTIR) and scanning electron microscopy (SEM).

\section{Experimental}

\subsection{Materials}

PVC resin with K-Wert value of 70 produced by CIRES (Portugal), dioctyl phthalate (DOP) from SGP (Tunisia), ethylene-vinyl-acetate (EVA) from BASF (Germany), acrylonitrile-butadiene-styrene (ABS) from Chemtura (USA), Zn and Ca stearates complex (Reapak BCV/3037) from IACN (Italy), and stearine produced by SO.G.I.S.SPA (Italy) were commercial products used without preliminary purification. The epoxidized sunflower oil (ESO) was especially prepared as described previously (Benaniba, Belhaneche-Bensemra, \& Gelbard, 2001). The level of oxirane oxygen was $5.2 \%$. The olive oil used as food simulant was first characterized. Its acidity index, iodine index, saponification index and peroxide index were measured, respectively, according to the ISO 660, ISO 3961, ISO 3957 and ISO 3960. The following characteristics were measured:

Acidity index $=1.38$; iodine index $=83.07$; saponification index $=182.9$; peroxide index $=7.5$ and relative density $=0.906$.

Ethanol and tetrahydrofuran (THF) of high purity grade from Prolabo were used as received.

\subsection{Preparation of PVC Films}

Samples were prepared according to the formulations given in Table 1. PVC and additives were mixed in a 
Table 1. Details on the prepared formulations (wt\%).

\begin{tabular}{|c|c|c|c|c|c|c|c|c|}
\hline & F1 & F2 & F3 & F4 & F5 & F6 & F7 & F8 \\
\hline PVC & 100 & 100 & 100 & 100 & 100 & 100 & 100 & 100 \\
\hline $\begin{array}{c}\text { Ca, Zn } \\
\text { complex }\end{array}$ & 2 & 2 & 2 & 2 & 2 & 2 & 2 & 2 \\
\hline ESO & 10 & 10 & 10 & 10 & 10 & 10 & 10 & 10 \\
\hline Stearic acid & 1 & 1 & 1 & 1 & 1 & 1 & 1 & 1 \\
\hline DOP & 40 & & & & & & & \\
\hline EVA & & 40 & & & & & & \\
\hline ABS & & & 40 & & & & & \\
\hline $\begin{array}{l}\text { DOP:EVA } \\
\text { DOP:ABS }\end{array}$ & & & & $30: 10$ & $25: 15$ & $20: 20$ & $15: 25$ & $10: 30$ \\
\hline
\end{tabular}

two-roll mill at $140^{\circ} \mathrm{C}$ and melt compressed at $170^{\circ} \mathrm{C}$ under a pressure of $300 \mathrm{kN} \cdot \mathrm{m}^{2}$.

\subsection{Migration Testing}

Circular samples having a thickness of $(2 \pm 0.1) \mathrm{mm}$ and a diameter of $(22 \pm 0.1) \mathrm{mm}$ were cut from the selected PVC films.

Migration tests were conducted using olive oil as fatty simulant and aqueous ethanol. The test conditions were 12 days at $40^{\circ} \mathrm{C}$ (directive 82/711EEC). Twelve circular samples of plasticized PVC were immersed in $120 \mathrm{ml}$ of food simulant. A circular sample and $10 \mathrm{ml}$ of food simulant were taken off every day. The rate of mass variation was calculated according to the following equation:

$$
\tau(\%)=\left[\left(m_{t}-m_{o}\right) / m_{o}\right] \times 100
$$

where: $m_{o}=$ initial mass before immersion and $m_{t}=$ mass of the sample at the time $t$.

The weights were measured to an accuracy of $10^{-4} \mathrm{~g}$.

\subsection{FTIR Analysis}

Polymeric film was recovered and analysed with a JASCO FTIR-430 spectrophotometer.

\subsection{SEM Characterization}

The PVC samples were analysed after metallization by a scanning electron microscope PHILIPS type ESEM XL.

\section{Results and Discussion}

\subsection{Migration Testing}

\subsubsection{Rate of Mass Variation}

The study of the rate of mass variation allows the identification of the interactions occurring between the PVC samples and the food simulants (olive oil and aqueous ethanol). The decrease in the rate of mass variation means that some amount of additives migrated from the PVC samples into the food simulant. The increase means a gain in mass or penetration of the food stimulant in the PVC samples.

Figure 1 illustrates the evolution of the rate of mass variation with time of contact in the case of the three considered formulations.

It is notable that in the case of aqueous ethanol the shape of the curves increases for the three formulations. This indicates the penetration of ethanol in the free volume. This phenomenon is facilitated by the low mass and low viscosity of ethanol. 
Moreover, in the case of olive oil, the shape of the curves decreases for the three formulations. This indicates that some additives have migrated.

Triglycerides are likely to interact with the lipophilic polymers and are good solvents for additives. They are weakly polar or apolar (Atek, Belhaneche-Bensemra, \& Turki, 2010). The presence of DOP plasticizer reduces the interactions between PVC chains and increases the free volume which increases the mobility of the additives and then promotes their diffusion. On the other hand, the results obtained show that the partial substitution of DOP plasticizer by both permanent plasticizers reduces migration. At the molecular level, the partial replacement of DOP by permanent plasticizers increases the cohesion between the two polymers chains and thereby reduces the free volume, which is unfavourable to the diffusion. This leads to a decrease in the migration of the additives.

Furthermore, Figure 1 shows clearly the following order concerning the migration of additives: DOP (40) > DOP:EVA (30/10) > DOP:ABS (30/10).

According to current legislation (Directive 90/128/EEC and its amendments; EEC 1990), the overall migration to a foodstuff from food contact plastics must be less than $10 \mathrm{mg}$ of plastics compounds per $\mathrm{dm}^{2}$ of surface area.

Table 2 shows the values of the overall migration in olive oil. They are lower than the maximum allowable overall migration: $10 \mathrm{mg} \cdot \mathrm{dm}^{-2}$. This means that migration has not affected the quality of the simulant (food). Moreover, the lowest values of global migration were obtained in the case of the formulations where there is an addition of a permanent plasticizer. This shows that this approach is effective in reducing the overall migration of additives.

\subsubsection{Migration Analysis by Infrared Spectroscopy}

The spectrum of PVC alone and the spectra of the additives were compared with the spectrum of PVC with additives. This allowed the identification of some characteristic bands which are related to the additives present in the formulation. Table 3 shows these bands (Boussoum, Atek, \& Belhaneche-Bensemra, 2006; Ito, Sechimi, Miura, Kawagushi, Saito, \& Nakazawa, 2006).

According to the phenomena of interaction between PVC samples and food simulants, the intensity of characteristic bands will change. An increase in the intensity corresponds to absorption of liquid through the PVC samples and inversely, a decrease in intensity corresponds to a migration of one or more components in the food simulants.

The comparison of the infrared spectra of the PVC films after various times of contact with the food simulants allowed to study the migration phenomenon both in qualitative and semi-quantitative terms. The different cha racteristic bands corresponding to the additives were identified.
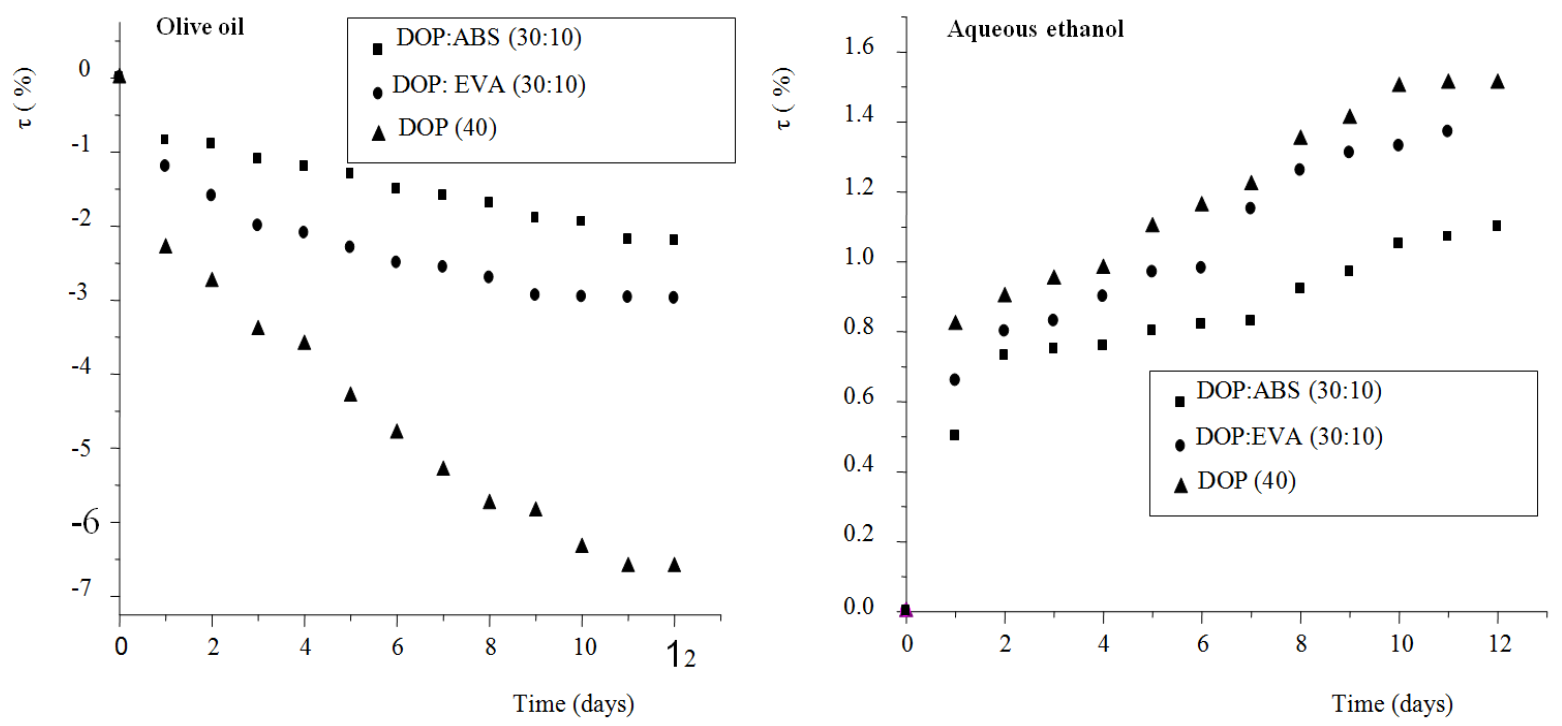

Figure 1. Effect of the nature of the food simulant on the rate of mass variation $\tau$. 
The following absorbance ratios were calculated:

A 1731/A 1426: ESO migration;

A 1719/A 1426: DOP migration;

A 1557/A 1426: Zn, Ca stearates complex migration;

A 1541/A 1426: Zn, Ca stearates complex migration;

A 1457/A 1426: Zn, Ca stearates complex, DOP, ESO and stearic acid migration.

The band at $1426 \mathrm{~cm}^{-1}$ is present in all the spectra. It is caused by the vibration of the $\mathrm{CH}_{2}$ bond in PVC (Krimm, Folt, Shipman, \& Berens, 1963). Figure 2 shows the variations of these five ratios of absorbance as a

Table 2. Overall migration $\left(\mathrm{mg} \cdot \mathrm{dm}^{-2}\right)$ in olive oil at $40^{\circ} \mathrm{C}$.

\begin{tabular}{cc}
\hline Formulations & ${\text { Overall migration }\left(\mathrm{mg} \cdot \mathrm{dm}^{-2}\right)}^{\text {DOP:EVA or ABS (40:00) }}$ \\
\hline DOP:EVA (30:10) & 1.36 \\
DOP:ABS (30:10) & 0.57 \\
\hline
\end{tabular}
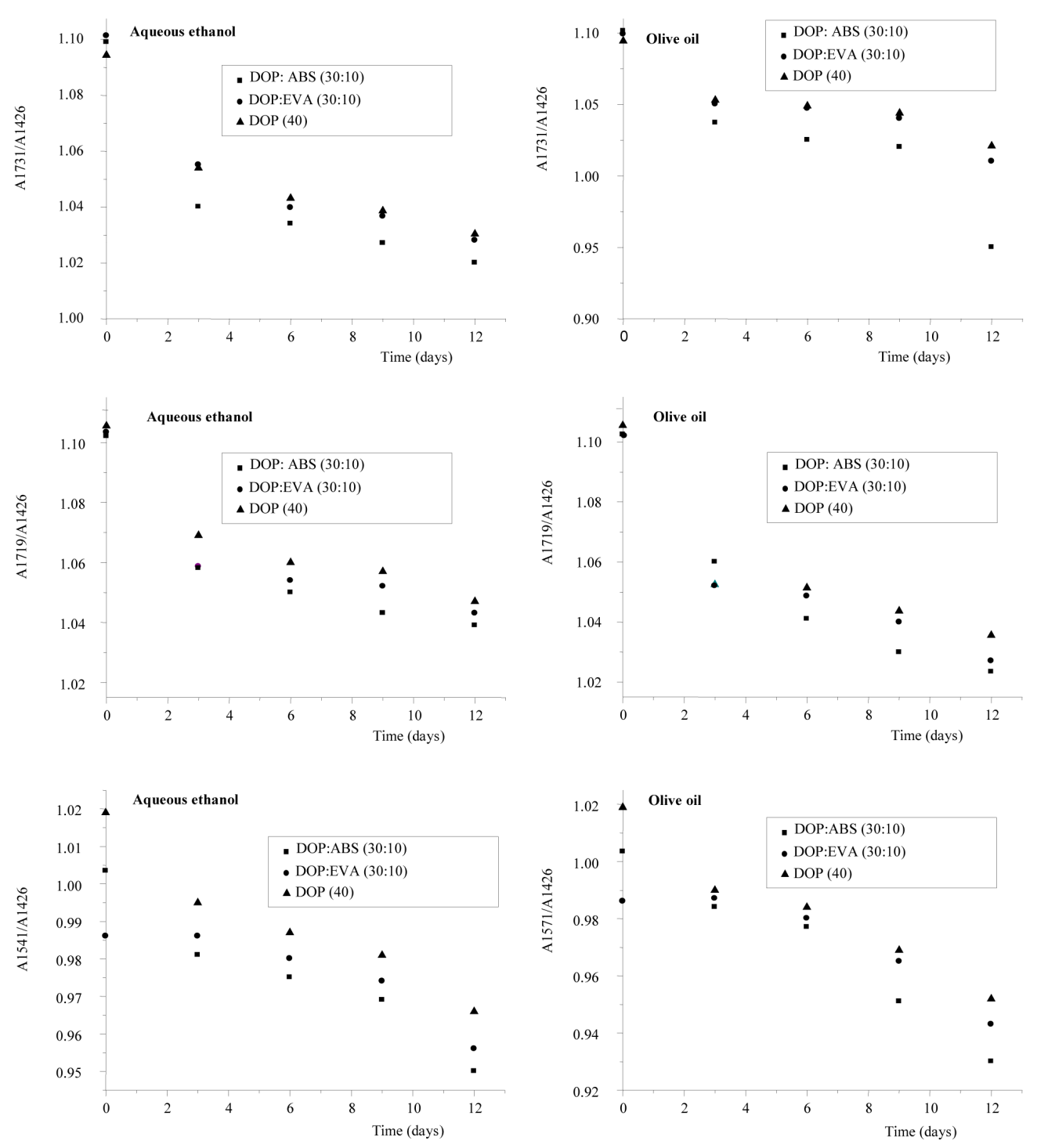

Figure 2. Variation of absorbance ratios as a function of time of contact with food simulants. 
function of time of contact with aqueous ethanol and olive oil for the three formulations studied.

There is a decrease in all absorbance ratios with time. This indicates that migration of ESO, Zn, Ca stearates complex, DOP and stearic acid occurred in both liquid simulants. In the case of aqueous ethanol, it seems that the penetration of the liquid simulant which was observed in the rate of mass variation favoured the migration of additives. The lowest ratios of absorbance were obtained for the formulation plasticized with DOP; therefore also, the lowest values of residual additives and the highest rates of migration. Furthermore, it appears clear that the partial substitution of DOP by the permanent plasticizers EVA and ABS reduced the migration of DOP and other additives.

According to the results obtained with rate of mass variation, the following order for the migration of additives estimated by FTIR spectroscopy was observed:

DOP (40) > DOP:EVA (30/10) > DOP:ABS (30/10).

\subsubsection{Morphological Analysis by SEM}

Figure 3 illustrates images of PVC samples of the three formulations analysed by scanning electron microscopy
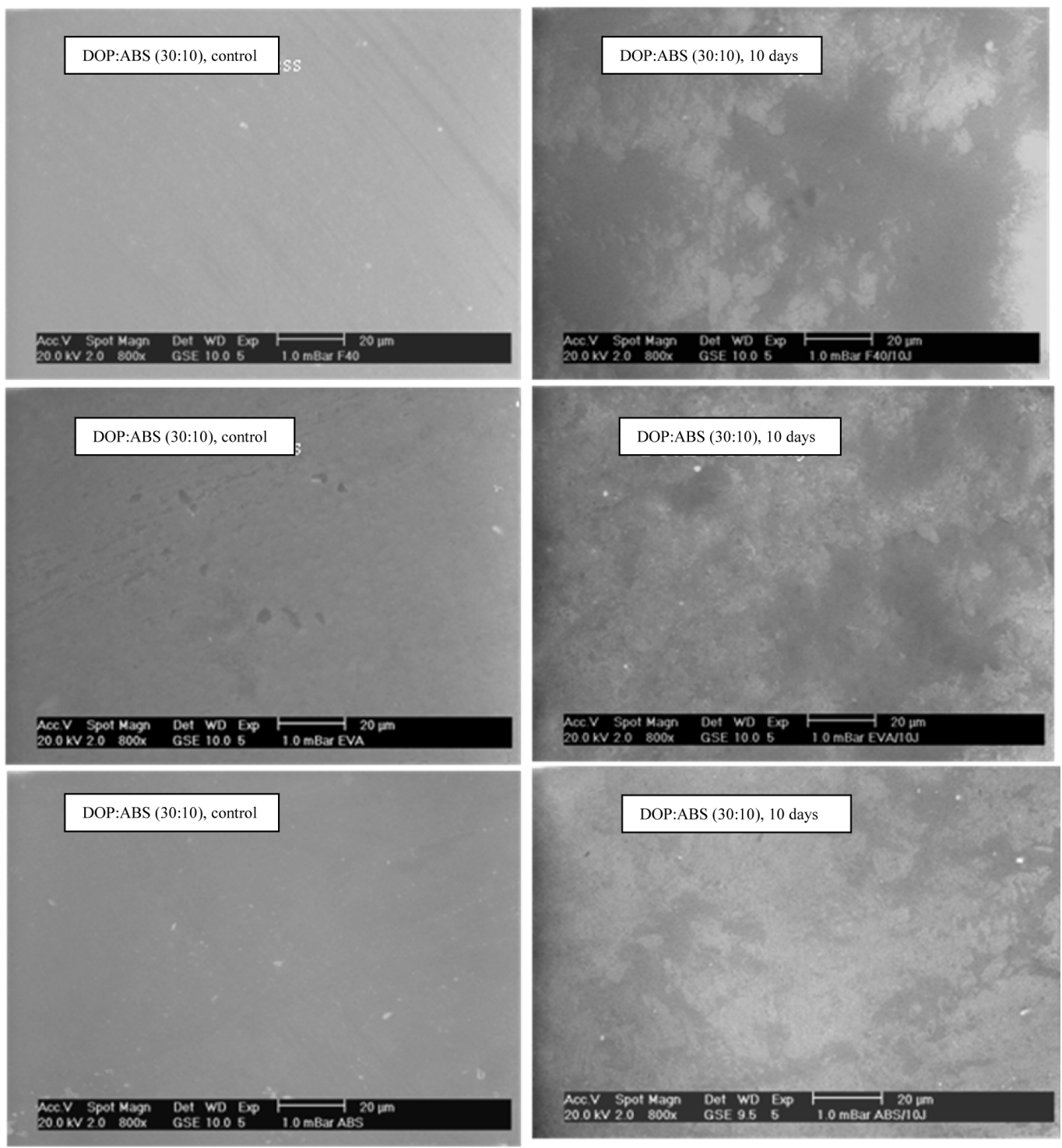

Figure 3. Analysis of plasticized formulations after migration testing in olive oil by scanning electron microscopy $(\mathrm{Gr} \times 800)$. 
Table 3. Characteristic bands of the used additives present in PVC film.

\begin{tabular}{cccc}
\hline $\mathrm{N}^{\circ}$ & Wave number $\left(\mathrm{cm}^{-1}\right)$ & Assignments & Additives \\
\hline 1 & 1731 & $\mathrm{C}=\mathrm{O}$ (ester) & ESO, EVA \\
2 & 1719 & $\mathrm{C}=\mathrm{O}$ (ester) & DOP \\
3 & 1557 & $\mathrm{COO}$ (ester) & Zn, Ca Complex \\
4 & 1541 & $\mathrm{CO}_{2}^{-}$ & (carboxylic acid salt) \\
5 & 1457 & $\mathrm{CH}_{2}$ (methyl, methylene) & Zn, Ca Complex \\
\hline
\end{tabular}

before and after contact with olive oil during 10 days. The surfaces of the samples after migration testing were rough compared to the control ones. The appearance of dark areas (holes) confirms that additives migration occurred.

The holes observed are more important in the case of the formulation DOP (40) than for the formulations DOP:EVA (30/10) and DOP:ABS (30/10) confirming that the additives migration is more important.

\section{Conclusion}

From the experimental results the following conclusions can be drawn:

- The preliminary study of the evolution of the rate of mass variations showed the presence of interactions between plasticized PVC and food simulants. Indeed, additives migration in olive oil and penetration of aqueous ethanol occurred. All the global migrations in olive oil found were lower than the allowable overall migration: $10 \mathrm{mg} \cdot \mathrm{dm}^{-2}$.

- $\quad$ The FTIR analysis has highlighted the migration of DOP and other additives using a semi quantitative estimation based on the evolution of the absorbance ratios versus contact time.

- The scanning electron microscopy confirmed that there was migration of additives in olive oil.

- Finally, this study showed the effectiveness of the approach consisting in the partial substitution of DOP by plasticizers of polymeric nature. All the results obtained with the various analytical methods used showed the following order concerning the migration of additives: DOP (40) > DOP:EVA (30/10) > DOP:ABS (30/10).

\section{References}

Atek, D., \& Belhaneche-Bensemra, N. (2005). FTIR Investigation of the Specific Migration of Additives from Rigid Poly (Vinyl Chloride). European Polymer Journal, 41, 707-714. http://dx.doi.org/10.1016/j.eurpolymj.2004.10.043

Atek, D., Belhaneche-Bensemra, N., \& Turki, M. (2010). Migration of Epoxidized Sunflower Oil and Dioctyl Phthalate from Rigid and Plasticized Poly(Vinyl Chloride). International Journal of Polymeric Materials, 59, 342-352. http://dx.doi.org/10.1080/00914030903478909

Audic, J. L., Reyx, D., Brosse, J. C., \& Poncin-Epaillard, F. (2000). Nouvelles approches pour contrôler la migration des aditifs dans les emballages alimentaires a base de PVC. Annales des Falsifications, de L'Expertise Chimique, 93, $201-214$.

Belhaneche-Bensemra, N., Zeddam, C., \& Ouahmed, S. (2002). Study of the Migration of Additives from Plasticized PVC. Macromolecular Symposia, 180, 191-202. http://dx.doi.org/10.1002/1521-3900(200203)180:1<191::AID-MASY191>3.0.CO;2-U

Benaniba, M. T., Belhaneche-Bensemra, N., \& Gelbard, G. (2001). Stabilizing Effect of Epoxidized Sunflower Oil on the Thermal Degradation of Poly (Vinyl Chloride). Polymer Degradation and Stability, 74, 501-505. http://dx.doi.org/10.1016/S0141-3910(01)00170-7

Boussoum, M. O., Atek, D., \& Belhaneche-Bensemra, N. (2006). Interactions between PVC Stabilised with Epoxidized Sunflower Oil and Food Simulants. Polymer Degradation and Stability, 91, 579-584. http://dx.doi.org/10.1016/j.polymdegradstab.2005.05.036

Cadogan, D. (2002). Health and Environmental Impact of Phthalates. Plastics Additives Compounding, 4, 28-29. http://dx.doi.org/10.1016/S1464-391X(02)80091-5

Conseil Oléicole International (2008). Norme commerciale applicable aux huiles d'olive et aux huiles de grignons.

Earls, A. O., Axord, I. P., \& Braybrook, J. H. (2003). Gas Chromatography Mass Spectrometry Determination of the Migra- 
tion of Phthalate Plasticizers from Poly Vinyl Chloride Toys and Chilcare Articles. Journal of Chromatography A, 983, 237-246. http://dx.doi.org/10.1016/S0021-9673(02)01736-3

Figge, K. (1972). Migration of Additives from Plastics Films into Edible Oils and Fat Simulants. Food and Cosmetics Toxicology, 10, 815-823. http://dx.doi.org/10.1016/S0015-6264(72)80008-7

Ito, R., Sechimi, F., Miura, N., Kawagushi, M., Saito, K., \& Nakazawa, H. (2006). Effect of Sterilisation Process on the Formation of Mono (2-Ethylhexyl) Phthalate from Di (2-Ethylhexyl) Phthalate. Journal of Pharmaceutcal and Biomedical Analysis, 41, 455-460. http://dx.doi.org/10.1016/j.jpba.2005.12.021

Krimm, S., Folt, V. L., Shipman, J. J., \& Berens, A. R. (1963). Infrared Spectroscopy and Assignment for Polyvinyl Chloride and Deuterated Analogs. Journal of Polymer Science: Part A, 1, 2621-2635.

Marcilla, A., Garcia, S., \& Garcia-Quesada, G.-C. (2004). Study of the Migration of PVC Plasticizers. Journal of Analytical and Applied Pyrolysis, 71, 457-463. http://dx.doi.org/10.1016/S0165-2370(03)00131-1

Marcilla, A., Garcia, S., \& Garcia-Quesada, G.-C. (2007). Migrability for PVC Plasticizers. Polymer Testing, 27, $221-233$. http://dx.doi.org/10.1016/j.polymertesting.2007.10.007

Marin, M., Lopez, J., Sanchez, A., Vilaplana, J., \& Jimenez, A. (1998). Analysis of Potentially Toxic Plasticizers Used in Toy Manufacturing. Bulletin of Environmental Contamination and Toxicology, 60, 68-73. http://dx.doi.org/10.1007/s001289900592

Mersiowsky, J. (2002). Long Term Fate of PVC Products and Their Additives in Landfills. Progress in Polymer Science, 27, 2227-2277. http://dx.doi.org/10.1016/S0079-6700(02)00037-0

Murphy, J. (2003). Additives for Plastics Handbook (2nd ed.). Oxford: Elsevier Advanced Technology.

Oil, L., Hersong, L. S., \& Madsen, J. O. (1997). Residential Exposure to Plasticizers and Its Possible Role in the Pathogenesis Asthma. Environmental Health Perspectives, 105, 972-978. http://dx.doi.org/10.1289/ehp.97105972

Rahman, M., \& Brazel, C. S. (2004). The Plasticizer Market: An Assessment of Traditional Plasticizers and Research Trends to Meet New Challenges. Progress in Polymer Science, 29, 1223-1248. http://dx.doi.org/10.1016/j.progpolymsci.2004.10.001

Wang, Q., \& Storm, B. K. (2005). Separation and Analysis of Low Molecular Weight Plasticizers, Poly (Vinyl Chloride) Tubes. Polymer Testing, 24, 290-300. http://dx.doi.org/10.1016/j.polymertesting.2004.12.002

Wilkinson, C., \& Lamb, J.C. (1990). The Potential Health Effects of Phthalates Esters in Children's Toys: A Review and Risk Assessment. Regulatory Toxicology and Pharmacology, 30, 140-155. http://dx.doi.org/10.1006/rtph.1999.1338

Zeddam, C., \& Belhaneche-Bensemra, N. (2010). Kinetic Study of the Specific Migration of an Oganotin Heat Stabilizer from Rigid Poly (Vinyl Chloride) into Food Simulants by FTIR Spectroscopy. International Journal of Polymeric Materials, 59, 318-329. http://dx.doi.org/10.1080/00914030903478867 